\title{
Instrumental Extraction by Obstetric Suction Cup at Nabil Choucair Health Center (Dakar, Senegal) from 2005 to 2016: Indications and Prognosis
}

\author{
Omar Gassama ${ }^{1,}$, , Mohamed Diadhiou ${ }^{1}$, Djibril Diallo ${ }^{1}$, Daouda Ndour ${ }^{3}$, Babacar Biaye ${ }^{1}$, \\ Margarita Christina Eyang El Abesso ${ }^{1}$, Taliana Stephie Gondjout ${ }^{1}$, Abdoul Aziz Diouf ${ }^{2}$, \\ Youssoupha Touré ${ }^{\text {, Philippe Marc Moreira }}{ }^{3}$, Marieme Gueye Ba ${ }^{1}$, Alassane Diouf ${ }^{2}$, \\ Jean Charles Moreau ${ }^{1}$
}

${ }^{1}$ Gynecologic and Obstetrics Clinic, Le Dantec Teaching Hospital, Cheikh Anta Diop University, Dakar, Senegal

${ }^{2}$ Gynecologic and Obstetrics Clinic, Pikine National Hospital, Dakar, Senegal

${ }^{3}$ Gynecologic and Obstetrics Clinic, Dalal Jamm Hospital, Guediawaye, Dakar, Senegal

Email address:

ogasse79@yahoo.fr (O. Gassama),ogasse1979@gmail.com (O. Gassama)

${ }^{*}$ Corresponding author

\section{To cite this article:}

Omar Gassama, Mohamed Diadhiou, Djibril Diallo, Daouda Ndour, Babacar Biaye, Margarita Christina Eyang El Abesso, Taliana Stephie Gondjout, Abdoul Aziz Diouf, Youssoupha Touré, Philippe Marc Moreira, Marieme Gueye Ba, Alassane Diouf, Jean Charles Moreau. Instrumental Extraction by Obstetric Suction Cup at Nabil Choucair Health Center (Dakar, Senegal) from 2005 to 2016: Indications and Prognosis. Journal of Gynecology and Obstetrics. Vol. 8, No. 2, 2020, pp. 35-38. doi: 10.11648/j.jgo.20200802.11

Received: February 11, 2020; Accepted: March 2, 2020; Published: March 17, 2020

\begin{abstract}
The objective of this study was to take stock of instrumental extractions using an obstetric suction cup at the Nabil Choucair Health Center in Dakar. It was a retrospective, descriptive study on instrumental extractions by vacuum cup from January 1, 2010 to December 31, 2017 (144 months) at the maternity unit of the Nabil Choucair Health Center. This study included all patients who had experienced vacuum assisted delivery. The parameters studied concerned socio-demographic, clinical characteristics, indications and maternal-foetal complications. The collection was carried out using the fact sheet completed on the basis of the analysis of the files, the delivery register, and the anaesthesia register of the operating room. Data entry was carried out using Sphinx version 5 software and data analysis by Epi info version 3.5 software and descriptive analysis was carried out by studying the frequency, the mean and the standard deviation. During the study period 66,000 women gave birth and we collected 360 instrumental extractions. The frequency of the vacuum cup was $0.5 \%$ for instrumental extractions. The average age of the patients was 24.5 years, parity was 1.6 . The average gestational age was 39.4 Weeks of Amenorrhea (SA), the average uterine height was $33 \mathrm{~cm}$, the noises of the foetal heart were normal in $98 \%$ of parturients. The indications were dominated by a stop in the progression of foetal mobile (39\%). The mean average birth weight was $2994 \mathrm{~g}$ and $97 \%$ of new-borns had an Apgar score of 9. Maternal complications were dominated by simple perineal tears (7\%) and 3 cervical tears (1.2\%). The neonatal prognosis was dominated by 13 caput succedaneum (chignon) (7\%). The obstetrics suction cup is still decisive for the foetal outcome in our maternities. The mastery of the technique and the right indications help to avoid complications.
\end{abstract}

Keywords: Obstetric Suction Cup, Dakar, Nabil Choucair, Senegal

\section{Introduction}

Instrumental extractions, including the suction cup, allow a good number of cases of obstructed labor to be settled during the expulsive phase of childbirth, thus avoiding a caesarean section. It should be remembered that the suction cup application is one of the seven functions of basic emergency obstetric and neonatal care, so it is a practice that can save the lives of mothers of new-born babies in developing countries [1]. In Africa in general and in Dakar in particular, 
studies on the vacuum cup are rare if not inexistent, this in connection with the infrequent use of this tool. This is why we proposed to carry out this work at the Nabil Choucair Health Center. It was a retrospective, descriptive and analytical study between January 1, 2005 and December 31, 2016, the main objective was to take stock of the instrumental extractions.

\section{Patients and Methods}

It was a retrospective, descriptive study conducted from January 1, 2005 to December 31, 2016, which represents a period of twelve years (144 months).

\subsection{Selection Criteria}

The target population was made up of all the women who gave birth by instrumental extraction by vacuum cup at the Nabil Choucair Health Center, making a workforce of 187 patients.

Included in this study were all women who delivered by vacuum cup during our study period.

The parameters studied concerned the socio-demographic parameters, the history of pregnancy, the admission data, the indications of the suction cup, the operator's qualification, the technique, the duration of the intervention, neonatal and maternal outcomes (Apgar score, birth weight, neonatal and maternal evolution) and maternal-foetal complications.

\subsection{Exlusion Criteria}

Incomplete records were secondarily excluded from the study.

\subsection{Statiscal Methods}

Information was gathered through a study of childbirth records, birth registers, surgical report books and anaesthesia records.

Data entry was carried out using Sphinx version 5 software and data analysis using Epi info version 3.5 software.

\subsection{Ethical Approval}

This study had the approval of the local ethics committee.

\section{Results}

During the study period, we performed 66,000 deliveries and 187 obstetric suction cups on 360 instrumental extractions, i.e. a frequency of $0.5 \%$.

\subsection{Socio-demographic Characteristics}

The average age of parturients was 24.5 years with a standard deviation of 5.5 and extremes 15 and 43. The median was 24 years. Patients were most often under 25 years of age $(47.9 \%)$ as reported in Figure 1.

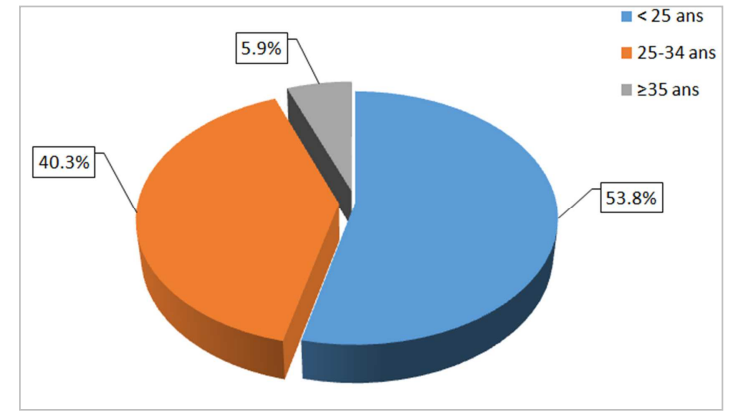

Figure 1. Distribution of patients by age group $(n=187)$.

Almost all of the patients were married (97.3\%).

The average gestation was 1.7 gestures with a standard deviation of 1.4 and extremes of 0 to 10 gestures. The patients were mainly primigravidae $(52.3 \%)$.

The average parity was 1.6 pares with extremes of 0 and 8 . Primiparous represented $63.5 \%$ of the cases.

\subsection{Clinical Data}

Completion of prenatal consultations was noted in almost all of the patients $(98.9 \%)$.

In our series fifty a woman $(27.9 \%)$ was referred. Refusal to evict was the main reason for referral (39.2\%).

The general condition was almost good in all the patients; only one patient had a fever and the mean blood pressure was $122 \mathrm{~mm} \mathrm{Hg}$ with extremes of 100 and $190 \mathrm{~mm} \mathrm{Hg}$.

The mean term of pregnancy was 39.4 weeks with a standard deviation of 1.2 and extremes of 37 and 43 weeks. The median was 39 weeks.

The mean uterine height was $33.1 \mathrm{~cm}$ with a standard deviation of 2.4 and extremes of 28 and $44 \mathrm{~cm}$. The median was $33 \mathrm{~cm}$.

The mean was 137.6 beats per minute with a standard deviation of 10.7 and extremes of 60 and 177. The median was 140 .

The mean dilation of the cervix on admission was $6 \mathrm{~cm}$ with extremes between 4 and $10 \mathrm{~cm}$.

The pelvis was clinically normal for all patients.

In our study the anterior left occipito-anterior was the most common position variety $(57 \%)$.

\subsection{Indications}

The average duration of the expulsion phase was 35.2 minutes with a standard deviation of 14.2 and extremes of 12 and 120 . The median was 35 .

Indications were dominated by halting progression $(39 \%)$ as reported Table 1.

Table 1. Indications of the vacuum cup.

\begin{tabular}{lll}
\hline Indications & Effective & Percentage \\
\hline halting progression & 73 & 39 \\
Maternal fatigue & 61 & 33 \\
The non-reassuring foetal & 35 & 19 \\
Cicatricial uterus & 15 & 8 \\
Eclampsia & 2 & 1, \\
Cardiopathy & 1 & 0,5 \\
\hline
\end{tabular}


i. Type of technique

The operators were all doctors in specialization (97.3\%)

In our study the occiput anterior is the most frequent $(97,9 \%)$ as reported Table 2 .

Table 2. Distribution of women by technique.

\begin{tabular}{lll}
\hline Type of technique & Effective & Percentage \\
\hline Occiput anterior & 184 & 97,9 \\
Occiput posterior & 3 & 1,6 \\
\hline
\end{tabular}

\subsection{Neonatal Data}

The average weight of the new-born was 2994 g. The median was 3100 grams.

The average Apgar score in the fifth minute was 9 with a standard deviation of 1 and extremes of 4 to 10 . The median was 9.

Foetal complications were noted in 13 new-borns (7\%). The latter were caput succedaneum (chignon).

Almost all of the new-borns (99.5\%) were alive and well.

ii. Maternal data

Almost all of the mothers (99.5\%) were alive and well. In addition, there was 1 case of death $(0.5 \%)$ secondary to a condition of eclampsia associated with HELLP syndrome.

Perineal tears were the main complications found $(7 \%)$. These tears were incomplete in 10 women, 1 st degree in 3 women as reported Table 3 .

Table 3. Distribution of women by fotal complications.

\begin{tabular}{lll}
\hline Maternal complications & Effective & Percentage \\
\hline Perineal tears & 13 & 7,0 \\
Bone lesions & 1 & 0,5 \\
\hline
\end{tabular}

\section{Discussion}

\subsection{Socio-epidemiological Characteristics}

Since the 1970s, instrumental extractions have experienced a significant decline worldwide. In Senegal, in Dakar at the Nabil Choucair Health Center, the average rate is $0.43 \%$. Studies carried out under the same socio-economic conditions have also found a gradual decline over the years: $1.6 \%$ in $1996,1.38 \%$ in 2008 [2, 3]. We have observed an inversely proportional increase in the rate of caesarean section which went from $12 \%$ of deliveries in 1992 to $17.5 \%$ in 1996 [2]. At the national level during a survey on Obstetric and Neonatal Emergency Care from 2012 to 2013, the national rate of caesarean is $4.4 \%$ compared to $0.2 \%$ for instrumental extractions [1]. The vacuum cup also experienced a drop in its practice with a rate of $0.2 \%$ in our series. This phenomenon is explained by the permanent unavailability of the instrument in our birthing rooms but also by the lack of skills for doctors in specializations. The majority of parturients were primiparous (63.5\%). In Senegal, several studies carried out in the same socio-cultural context had found respectively $60.1 \%, 64.4 \%$, and $71.7 \%$ of primiparous women [3-5]. In France, Gerbers had found $80 \%$ of primiparous women [6]. This predominance of primiparous is explained by the ignorance of pushing efforts, maternal fatigue and the systematic use of epidural anaesthesia during childbirth in developed countries [7].

\subsection{Indications, Operating Technique, Type of Instrument and Duration of Instrumental Extractions}

In our series, the indications were dominated for a stop in the progression of the foetal mobile in $39 \%$ and for maternal fatigue in $33 \%$. Stopping progression at all levels of excavation, especially if there is a defect in bending which is associated with a defect in rotation. Progression stops at the level of the middle strait are defects of rotation from a posterior position in transverse and the complement of flexion allows the rotation towards an anterior variety and therefore the delivery by the base way. Other authors have found the predominance of maternal fatigue in the indications for instrumental extractions [2, 4, 5]. They are generally primiparous with uncoordinated and ineffective expulsive efforts with lack of cooperation due to the lack of preparation for birth in our societies. Riethmuller considers that the suction cup is not a good indication for maternal fatigue because it requires the participation of the parturient. The non-reassuring foetal state the third indication in our series (19\%) and can be superimposed on the results of several authors $[3,8]$. The recommendations for clinical practice of the National College of French Obstetrician Gynaecologists mention the non-reassuring foetal state as the main indication for instrumental extractions [5]. Obstetric vacuum seems to be a good indication and this is shown by a prospective cohort study which assessed the $\mathrm{pH}$ at the level of the umbilical artery and had not found any significant difference for new-borns delivered by caesarean and those extracted by suction cup [9]. The difference in indications is explained by the early and sometimes "abusive" diagnosis of acute foetal distress in developed countries thanks to labor monitoring means such as recording foetal heart rate, foetal blood $\mathrm{pH}$ after micro puncture of the scalp. On the other hand, in our context, we use clinical means such as the auscultation of the sounds of the heart of the foetus by the Pinard stethoscope and the changes in colouring of the amniotic fluid [10].

\subsection{Prognostic Aspects}

\subsubsection{Maternal}

In our series, $73.6 \%$ of parturients had an episiotomy. This frequency is lower than that found by several authors $[3,11]$ $(92.2 \%)$ or even Menard et al. (80.2\%) [12]. Indeed, the systematic practice of episiotomy during instrumental extractions is a subject of controversy. The publication of the article by Leeuw [11] et al in the British Journal of Obstetrics and Gynaecology at the beginning of 2008 called into question the recommendations for clinical practice of CNGOF of 2006 [5] which recommended not to use in a liberal way of the episiotomy during an instrumental extraction but to let the clinical good sense of the practitioner guide the recourse or not to this perineotomy. Indeed, this important study of the Dutch register on nearly 33,000 
instrumental extractions concluded that episiotomy reduces the risk of tears of the anal sphincter in the event of instrumental extractions.

Cervical tears are rarely involved in the occurrence of postpartum haemorrhage during instrumental extractions [7].

\subsubsection{Neonatal}

In our study, 97\% of new-borns had an Apgar score of 9 by the fifth minute. This good Apgar score proves that the instrumental extraction is not very traumatic if the indications are well laid, the conditions of application respected and the technique mastered. [2, 3, 5, 13].

In our series, foetal morbidity was dominated by the caput succedaneum (chignon), which is a minor lesion often not specific to instrumental extractions [13]. Claris reports that the timeliness of the indication and the skill of the operator greatly influence the neonatal prognosis [14].

\section{Conclusion}

Instrumental extractions like obstetric suction cup are practiced less and less in our maternity hospitals, but they may be necessary to correct certain anomalies of the work in particular the defects of expulsion and / or the birth of a suffering foetus.

\section{References}

[1] MSAS- UNFPA- OMS- UNICEF- CEFOREP. Evaluation des besoins en Soins Obstétricaux et Néonatals d'Urgence au Sénégal de 2012-2013 Rapport, Dakar, Décembre 2014, 179p.

[2] Cisse C. T, Ewaginon E, Fotso A, Maitournam F, Moreau J. C, Diadhiou F. Indications et pronostic de l'accouchement par forceps au CHU de Dakar. Dakar Med, 1998; 43 (2): 220-224.

[3] Diouf A. B. Épidémiologie et pronostic des extractions instrumentales à la maternité de l'Institut d'Hygiène Sociale de Dakar. Mémoire Med, 2010, Numéro 258.
[4] Ndao D. Accouchement par forceps au Sénégal: résultats trois enquêtes sur la couverture obstétrico-chirurgicale du pays. Thèse Med, $N^{\circ} 03$, Dakar, 2007: 112p.

[5] Sow D. B. Pronostic de l'accouchement par ventouse obstétricale au Centre Hospitalier National de Pikine. Thèse Med, 2013, Numéro 99.

[6] Gerbers V. Y, Hohlfeld P. Pronostic maternel et néonatal lors d'une deuxième phase d'accouchements prolongée. J Gynecol Obstet Biol Reprod 1999; 28 (2): 145-50.

[7] College National Des Gynécologues Obstétriciens Francais. Texte de recommandations. Extractions instrumentals $\mathrm{La}$ Revue Sage-Femme, 2009; 8: 104-107.

[8] Bergsjo P. Differences in the reported frequencies of some obstetrical interventions in Europe. Br. J Obstet Gynaecol 1983; 90: 628-32.

[9] Riethmuller D, Ramanah R, Maillet R, Patrick J. P Ventouses: description, mécanique, indications, contre-indications Journal de Gynécologie-Obstétrique et Biologie de la Reproduction (2008): 37 S210- S221.

[10] Vinzileolos and al Effect of vacuum extractor on ombilical cord blood acid base measurments J Mater Fet Med 1996; 5: $11-7$.

[11] Leeuw. Mediolateral episiotomy reduces the risk for anal sphincter injury during operative vaginal delivery. BJOG 2008; 115: 104-108.

[12] 12 Menard J, Provansal M, Heckendroth H, Gamere M, Bretelle $\mathrm{F}$ and al Morbidité maternelle immédiate après extraction instrumentale par spatules de Thierry et par ventouse obstétricale. Gynecol Obstet Fertil 2008. 2008; 36: 623-7.

[13] Boni Serge, Abauleth R, Gondo D, Koffi A, Effoh D, Kone N. Indications des extractions instrumentales et pronostic foetomaternel au CHU de Cocody. J de la SAGO, 2005; 6 (1): 1-5.

[14] Claris O. Les risques du forceps: le point de vue du pédiatre et de l'obstétricien. Rev. Fr. Gynecol. Obstet, 1990; 85 (10): 549-551. 